\title{
The Effect of Mindset on Tourist Behaviour and Mindful Consumption in a Community Enterprise in Krabi, Thailand
}

\author{
Sudjai Jirojkul ${ }^{1}$, Siwarit Pongsakornrungsilp ${ }^{2}$, Nontipak Pianroj ${ }^{3}$, \\ Prachyakorn Chaiyakot ${ }^{1}$, Shahin Mia ${ }^{4}$, Tawakul Masst ${ }^{5}$, Kuaanan Techato ${ }^{1}$ \\ ${ }^{1}$ Faculty of Environmental Management, Prince of Songkla University, Hat Yai Campus, Thailand \\ ${ }^{2}$ The Center of the Excellence for Tourism Business Management and Creative Economy, \\ School of Management, Walailak University, Thailand \\ ${ }^{3}$ Faculty of Liberal Arts and Management Science, Prince of Songkla University, Surattani Campus, \\ Thailand ${ }^{4}$ School of Economics, Finance and Banking (SEFB), Universiti Utara Malaysia (UUM), \\ 06010, Sintok, Kedah, Malaysia \\ ${ }^{5}$ Department of Philosophy, Faculty of Social Science, University of Karachi, Pakistan
}

\begin{abstract}
The research examined the mindful consumption theory, focusing on the importance of sustainable consumption in the tourism sector in the future. An exploratory factor analysis of survey responses from 400 tourists who travelled to a community in Krabi, Thailand, revealed that the mindful mindset consists of four factors and mindful behaviour consists of six factors. A confirmatory factor analysis found that the adapted model corresponded to the empirical data and confirmed that the factors identified in the exploratory analysis were accurate.
\end{abstract}

Keywords - Mindful consumption, Mindful mindset, Mindful behaviour, Intangible value, and Social initiative.

\section{Introduction}

Social and environmental problems are partly generated by economic pressures that make people

DOI: $10.18421 /$ TEM103-11

https://doi.org/10.18421/TEM103-11

Corresponding author: Kua-anan Techato,

Faculty of Environmental Management, Prince of Songkla University, Hat Yai Campus, Thailand.

Email: kuaanan.t@psu.ac.th

Received: 19 February 2021.

Revised: 10 July 2021.

Accepted: 16 July 2021.

Published: 27 August 2021.

(c) BY-NC-ND (C) 2021 Kua-anan Techato et al; published by UIKTEN. This work is licensed under the Creative Commons Attribution-NonCommercial-NoDerivs 4.0 License.

The article is published with Open Access at www.temjournal.com struggle to become the market leader and get more power in their businesses [1]. This affects how communities and their environments are changed in both positive and negative ways [2], which community members and tourists are increasingly knowledgeable about, as shown in several studies [3]. Learning, perception and awareness of the effects in the cognitive and affective domains are the main factors influencing the behaviour of tourists [4]. Factors that persuade tourists to visit an area include the integrity of the natural resources, the original community ways and culture [5], referenced person [6], beautiful attractions, and convenient transportation [7]. These factors cause a shift in the mindset of tourists. Shaw and Williams [8] state that new groups of tourists, especially middle-class tourists with more knowledge and more restraint (also called 'new petit bourgeoisie' or Post-Fordist tourists), are interested in quality orientation, the consequences of their activities, and aesthetic aspects of life. Moreover, they give importance to hedonistic and personal experiences [9]. The mindset of these tourists is reflected in marketing that focuses on emotional engagement or on the intangible value [10] of tourism organised in community-based businesses and on the satisfaction of tourists by creating unique community-based experiences. Additionally, Pongsakornrungsilp [11] states that the value creator is the customer. Using and owning products (value in use) and the intangible value of the products result in the power of the customer, which increasingly affects the marketing of producers. Similarly, current sustainability strategies are incapable of leading to sustainability because they fail to solve overconsumption and do not integrate management within the communities [12]. Therefore, communitybased tourism should devolve business management to community members and focus on consumers to reduce and solve the problems. 


\subsection{Mindset and Mindful Consumption to Mindful Tourism}

Mindful consumption is a framework for studying the behaviour of consumers that is adapted to study the behaviour of tourists in this research. This concept, outlined by Sheth et al. [9], includes the principle of finding solutions by focusing on consumers who demonstrate overconsumption behaviour. It is the proper tool to manage the required value to the economy, society and the environment for the purpose of customer-centric sustainability. Additionally, mindful consumption is based on a mindset, including attitudes, values and expectations. This mindset guides the consumer to integrate a sense of caring about their own consumption into their personality. It relates to and affects (1) people, (2) communities and (3) nature, and it results in the control of acquisitive, repetitive and aspirational consumption.

Mindset is the most important personal factor related to tourists' behaviour. Psychological theories of behaviour show that behaviour is based on cognition, especially the rational and emotional interpretation and evaluation of data and situations [24]. It is a part of the decision-making process of consumer and tourist behaviour. Research has revealed that tourist groups each have different purposes for travelling and different sources of their decisions to express their behaviour depending on the moment and the situation [13].

The theory of planned behaviour (TPB), as presented by Ajzen [14], shows that human behaviour is influenced by intentions such as the desire to pay more if the tourism activities or services can reduce their impact on communities or the environment. The intentions of this behaviour consist of attitudes toward the behaviour, subjective norms about the behaviour, and perceived control of the behaviour, including attitudes about attractions and destinations.

Studies of human behaviour show that humans express behaviour reflecting part of the truth or their needs at that moment because they are able to vary their decision making and express behaviour against an intended plan. We mostly behave in a simple way, which is to get the highest satisfaction based on experience. This is associated with Gollwitzer's theory of implementation intention [15], which reveals that habits have an influence over attitudes, norms, behavioural controls, and intended behaviours. Habits are generated and continued automatically without a decision process. On the other hand, behaviour expression or behaviour change following TPB is under conscious control [16]. To control a habit is to express a behaviour through a decision process by using reasonable thought. This lets a person express their behaviour by using goal setting and action planning (what, where, when, who, and how) to achieve that goal [16]. This process will help us to consider the expression of behaviour through conscious control applied with TPB to reduce the decision errors of habitual behaviour. The results from a study of tourist behaviour related to the hypothesis of Schwartz [17] found that humans tend to develop behaviour well, even from the perspective of environmentalists. They point out that humans understand and believe in the value of nature from environmental impacts that are occurring today. Therefore, Schwartz presents the norm activation theory with the principle that human behaviour or behaviour change supports the planned goal only when humans have the right consciousness, and that behaviour change is linked to the expectation of subsequent events. This is the result of inner values, beliefs, perceptions, and personal norms. Behaviour change is achieved through the motivation of personal moral norms and the acceptance of personal values. For example, the ecological worldview suggests that we are in a crisis due to a lack of awareness of consequences, ascription of responsibility, and belief that the impacts can be reduced by changing behaviour. According to the Value-Belief-Norm theory [18], behaviour change occurs in four forms, which are activism, non-activist public-sphere behaviour, private-sphere behaviour, and behaviours in organisations. Moreover, studies by Wheale and Hinton [19] and Young et al. [13] support the view that knowledge and perception of the environment is an essential factor causing tourists to buy green products and show more consumer ethics. This shows that tourist behaviour is influenced by understanding the value of things and the impacts of irresponsible actions that affect communities, society, and the environment.

The key to development is the growth mindset inside the person who believes that learning can raise intelligence and ability levels, as well as the person who loves challenges and views problems as an opportunity for development. Self-development and constantly learning new things help the brain to connect new things with experiences and to gain more intelligence. Developing a growth mindset is a modern psychological tool that stands in contrast to the outdated belief that admiration for the intelligence of children does not give the child more confidence and learning abilities. On the other hand, a growth mindset is a psychological framework for success [20]. It is the cognitive process that leads to a meaningful and purposeful life. In terms of marketing, Murphy and Dweck [21] say that mindset is important to understand consumer behaviour because it has the power to attract and influence the 
attention of consumers. Moreover, it influences the perception and acceptance of the impacts of consumer change. It also plays an important role in the perception and experience among groups and self-enhancement through the use of unique, outstanding and revered products [22].

Mindful consumption is customer-centric and focuses on building relationships with consumers by releasing products and services matching the value that customers expect to receive based on previous announcements or advertisements [23]. It is necessary to understand the needs, expectations, and satisfaction of customers in order to create attractive products that encourage them to purchase or travel. It is also important to arrange products and services appropriate to consumer expectations [24] by using effective communication. It presents the idea that tourists expect entrepreneurs to be experts in the service or product more than in other businesses, and that they have the ability to continually create and innovate [25]. Murphy and Dweck's [21] conceptual framework of consumer behaviour notes that fulfilling the expectations of consumers supports the development of relationships between products, brands and organisations as well. This is because if consumers have a growth mindset, they will seek useful products that support their goals and help them continue learning new things in the future. Therefore, products and services have to increase their efficiency to encourage consumers to develop or expand their core aspects of products and services. The concept of mindful consumption is generated by a mindful mindset that leads to mindful behaviour. In this case, behaviour refers to an action or expression of the body, knowledge, thoughts or mind. Behaviour is created by a stimulus-response, causing adaptations to survive in a constantly changing society and affecting the performance of lifelong learning behaviours [26], including curiosity, willpower, challenge, proactive learning, and citizenship. These behaviours will guide the development of sustainable behaviours in the future.

Mindful consumption leads to the goal of sustainable consumption by emphasising the mindset and behaviour modification of consumers. The intention is to study the use of mindful consumption in marketing and to find ways to reduce and solve the consequences of overconsumption [27]. Consumers will be able to change their mindsets and behaviours successfully by creating awareness using mindset inculcating, guiding ideas, and shaping behaviours that contribute to sustainable consumption. It shows the whole mindful mindset and mindful behaviour with good intentions and good hopes for one's wellbeing in accord with one's values [9]. A mindful mindset is a framework for caring for oneself, a community, and for nature. Caring for oneself includes seeing yourself positively, looking for mental happiness, being proud to be self-confident and being self-reliant [25]. Caring about a community means having good feelings towards that community and its well-being, happiness, unity and ability to defend itself against external pressures [28]. Regarding the ecological value of nature as a source and a sink, also known as the ecological service and aesthetic value, caring for nature is valuable and should be maintained [29]. A mindset of caring for oneself, a community, and nature is attractive as it motivates consumption control planning and goal setting. It is important to increase positive motivation, which is not easy. Mindful behaviour is the expression of new behaviours in response to the desire to change or create a new identity. The essence of mindful consumption is the temperance to balance things that will be consumed, and it needs to be practised in three types, which are accumulative, repetitive and aspirational consumption. First, acquisitive consumption involves controlling consumption and not consuming with greed. Repetitive consumption involves reducing the consumption of disposable products [30] and fashionable products by turning to the trend of reuse, leading to product sustainability [31]. Aspirational consumption involves controlling consumption for social competition by comparing the value with the quality of the product rather than as a luxury [32]. These behavioural controls encourage consumers to consciously consume by caring not only about their satisfaction and gratification. It contributes to reasonable and mindful consumption.

Marketing with mindful consumption as the priority (MC-oriented marketing) is an important marketing concept to develop consumers. The mindful mindset leads to mindful and consciously expressed behaviour that has repercussions towards emotional values and consumer perceptions. It affects the development of the growth mindset of the consumer to be continuously better, as shown in Figure 1.

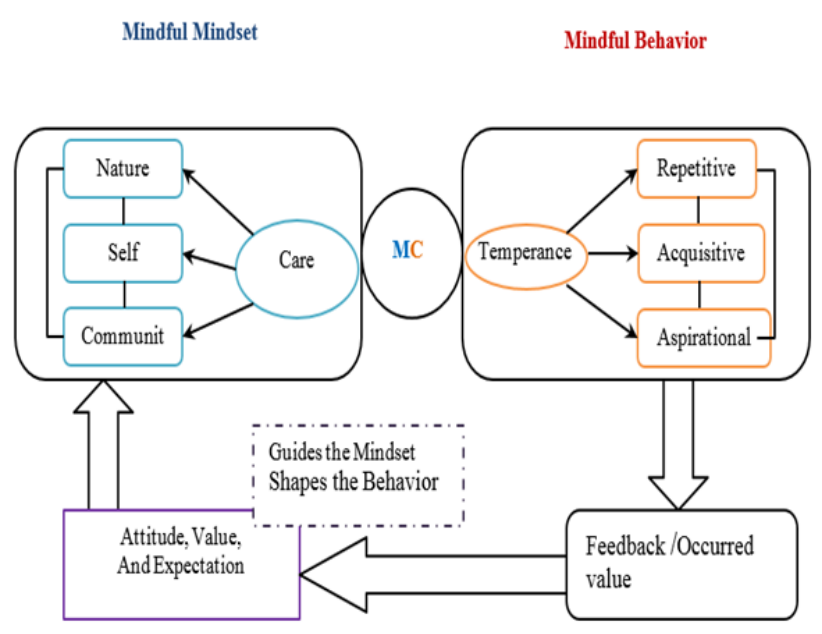

Figure 1. Systematic of Mindful Consumption 
In terms of entrepreneurship, Gordon \& Schaller [33] found that the intrapersonal mindset of entrepreneurs, personal factors, and environmental factors affect entrepreneurial cognitive processing and decision making in emergency situations. Consequently, the mindset is of great importance for both producers and consumers to make decisions about behavioural expression that can be applied to develop community tourism and entrepreneurship if there is the right understanding.

\subsection{Community - Based Tourism to Sustainable Tourism}

Community-based tourism involves the development of a community using tourism as a tool and using human resources in the community to manage natural, cultural, and intellectual resources in the area. The aim is to benefit the economy and the lives of people in the community while managing the environmental impacts. People in the community own the process and participate in planning, making decisions, taking actions, and accepting the consequences together [34]. Community-based tourism will be sustainable if entrepreneurs show the ability to manage the development of tourism in parallel with economic stability and also care for the community and the environment in accordance with Our Common Future [35], which outlines the need to operate and build with peace and partnership regarding sustainable development goals.

To achieve sustainable tourism management, the main principles are to minimise waste by using an efficient energy management system to reduce carbon emissions and hazardous waste, to maintain natural resources and protect abundance and diversity, and to increase participation in the management of various sectors [36]. Today, many people have a different perspective on tourism. Tourism must be responsible and environmentally friendly. Moreover, it must create economic opportunities and improve the quality of life for the community members. Hudson found that tourists are increasingly environmentally responsible due to environmental problems, natural disasters, and politics. Therefore, they understand the importance of participating in the protection of the environment and of seeking tourism activities with social and environmental responsibility, even if they are more expensive than the services of less impactful establishments, in order to avoid negative consequences.

In addition, there is some research regarding the value of tourism. For example, Jamal et al. [8] found that factors affecting tourist perceptions of value are (1) the functional value of establishment, (2) the functional value of price, (3) the experiential value of the host-guest interaction, (4) the experiential value of activity in terms of culture and knowledge, and (5) the emotional value. The results of the study show that functions, emotions and experiences are perceived as the values of community tourism. Furthermore, Young et al. [13] found that the purchasing behaviour of green consumers is different based on the time period. The purchasing experience, knowledge of the purchasing process and the guilt of not purchasing a green product cause feedback on the value and knowledge of consumers. Additionally, Young et al. [16] found that what encourages green consumers to be more ethical is the value created by the strength of the shopping experience, their perception and knowledge of the impacts, and the value of the product being reasonable. However, the key is that the mindset of consumers must be strengthened and have positive effects. Entrepreneurs must therefore pay more attention to these factors [13].

\section{Methodology}

The quantitative research with questions regarding mindful consumption principles and the value of tourism in a natural tourism community consisted of two parts. The first part was about a mindful mindset, including notions arising from the perception of caring experiences for oneself, a society or a community, and the environment. The second part was about mindful behaviour, including tourist caring behaviours. The questionnaire contained questions with answers on a 5-point scale from highest to lowest.

Data was collected from 400 tourists who visited the ecotourism community operated by Ban Tung Yee Peng tourism community business, Koh Lanta, Krabi. The answers were analysed to confirm the factors comprising the mindful mindset and mindful behaviour. The sample of tourists included 208 males and 192 females. There were 19 Thai tourists and 381 foreign tourists.

\section{Results}

The observed variables comprising the mindset and behaviour of the tourists based on the principle of mindful consumption were analysed. Exploratory factor analysis and confirmatory factor analysis under the agreement of data analysis by maximum likelihood estimation (MLE) found that the observed variables had a multinormal distribution. According to the principle of empirical data consistency analysis, the straightness of the observed variables model can be attributed to a normal distribution qualification [37]. 
Table 1. Kaiser-Meyer-Olkin Measure of Sampling Adequacy (KMO) and Bartlett's Test of Sphericity for the correlation matrix of the mindful mindset variables

KMO and Bartlett's Test

Kaiser-Meyer-Olkin Measure of Sampling Adequacy.

Note: MSA is appropriate for factor analysis [37]

Bartlett's Test of Sphericity

Approx. Chi-Square

df

Sig.
2039.42

.00
Table 1 shows the Kaiser-Meyer-Olkin measure of sampling adequacy (KMO) was 0.80 , and Bartlett's test of sphericity was statistically significant ( $\mathrm{Sig}=$ $0.00)$. The observed factor correspondence was statistically significant at .00, which is less than 0.05 , indicating that the correlation matrix of the mindful mindset variables was appropriate for factor analysis [25].

Exploratory factor analysis of the mindful mindset considers the commonality of the observed variables, which is a correlation between variables. With values from 0.52 to 0.78 , it indicated that the variables can explain the variations of other variables and can be placed in any of the factors. All 32 of the observed mindful mindset variables were analysed. Factor rotation with the varimax method was used to find which variables should be in which factors. It was determined that only factor loading up to 0.5 would be included, and unqualified variables were eliminated. There were 14 variables in four factors, as shown in Tables 2 and 3.

Table 2. Eigenvalues, Percentage of variance explained, Cumulative percentage of each factor of the mindful mindset

\begin{tabular}{c|l|c|c|c}
\hline Factor & \multicolumn{1}{|c|}{ Names of factors } & Eigenvalues & $\begin{array}{c}\text { Percentage of } \\
\text { variance explained }\end{array}$ & $\begin{array}{c}\text { Cumulative } \\
\text { percentage }\end{array}$ \\
\hline 1 & Value of community & 4.33 & 30.89 & 30.89 \\
2 & Value of natural resources & 2.28 & 16.27 & 47.16 \\
3 & Value of tourism to a community & 1.32 & 9.39 & 56.55 \\
4 & Personal mindset & 1.19 & 8.51 & 65.06 \\
\hline
\end{tabular}

Table 3. Factors and Observed variables

\begin{tabular}{|c|c|c|c|c|}
\hline \multicolumn{3}{|r|}{ Factors } & \multicolumn{2}{|r|}{ Observed variables } \\
\hline No. & Factors & Name of factors & Factors & Description/Question in the questionnaire \\
\hline \multicolumn{5}{|c|}{ Mindful mindset (variable: mindset) } \\
\hline \multirow[t]{4}{*}{1} & $\mathrm{~mm} 1$ & Value of community & $\mathrm{m} 7$ & $\begin{array}{l}\text { When travelling in a community, tourists must } \\
\text { respect the culture and ways of the community }\end{array}$ \\
\hline & & & $\mathrm{m} 6$ & $\begin{array}{l}\text { Tourism must not adversely impact the } \\
\text { community or ruin the environment }\end{array}$ \\
\hline & & & $\mathrm{m} 8$ & $\begin{array}{l}\text { The community way of life has value and an } \\
\text { identity that should be preserved }\end{array}$ \\
\hline & & & $\mathrm{m} 9$ & $\begin{array}{l}\text { There is a source of knowledge and valuable } \\
\text { natural resources that are worth preserving }\end{array}$ \\
\hline \multirow[t]{4}{*}{2} & $\mathrm{~mm} 2$ & Value of natural resources & $\mathrm{m} 14-2$ & $\begin{array}{l}\text { Abundant resources are valuable as a means of } \\
\text { life and a food source for the community }\end{array}$ \\
\hline & & & $\mathrm{m} 15$ & $\begin{array}{l}\text { Natural resources and the environment are } \\
\text { related to culture and community life }\end{array}$ \\
\hline & & & m14-1 & $\begin{array}{l}\text { Abundant resources are valuable to attract } \\
\text { tourists }\end{array}$ \\
\hline & & & $\mathrm{m} 16$ & $\begin{array}{l}\text { Natural resources provide human psychological } \\
\text { pleasures }\end{array}$ \\
\hline \multirow[t]{4}{*}{3} & $\mathrm{~mm} 3$ & $\begin{array}{l}\text { Value of tourism to a } \\
\text { community }\end{array}$ & m5-3 & $\begin{array}{l}\text { Value is gained from tourism in the host } \\
\text { community / traditional community }\end{array}$ \\
\hline & & & & $\begin{array}{l}\text { Tourism helps the community to be proud and } \\
\text { have self-esteem }\end{array}$ \\
\hline & & & $\mathrm{m} 5-2$ & $\begin{array}{l}\text { Tourism helps to preserve the culture and the } \\
\text { way of life of the people in the community }\end{array}$ \\
\hline & & & m5-4 & $\begin{array}{l}\text { Tourism helps to build strength and unity of the } \\
\text { people in the community }\end{array}$ \\
\hline
\end{tabular}




\begin{tabular}{|c|c|c|c|c|}
\hline \multicolumn{3}{|c|}{ Factors } & \multicolumn{2}{|r|}{ Observed variables } \\
\hline No. & Factors & Name of factors & Factors & Description/Question in the questionnaire \\
\hline \multicolumn{5}{|c|}{ Mindful mindset (variable: mindset) } \\
\hline & & & $\mathrm{m} 2-4$ & $\begin{array}{l}\text { tourists' achievements? } \\
\text { Use of an ability to achieve a goal and an } \\
\text { effective result }\end{array}$ \\
\hline & & & $\mathrm{m} 2-3$ & $\begin{array}{l}\text { A feeling of ownership in the natural resources } \\
\text { affecting the achievement }\end{array}$ \\
\hline & & & $\mathrm{m} 2-6$ & $\begin{array}{l}\text { A positive attitude affecting working and } \\
\text { learning }\end{array}$ \\
\hline
\end{tabular}

$\left(\chi^{2}\right)=76.97, d f=7, P=0.06, G F I=0.97, A G F I=0.95, R M S E A=0.3, C N=456.93$

Confirmatory factor analysis of the mindful mindset factor model showed that the modified model was consistent with the empirical data considering the chi-square $(\chi 2)$ of 76.97. The number of degrees of freedom (df) was 59. The statistical significance (P-value) was 0.06 , greater than 0.05 , meaning the chi-square was statistically insignificant. The goodness of fit index (GFI) was 0.97, and the adjusted goodness of fit index (AGFI) was 0.95, which is better than the specified criteria. The root mean square residual (RMR) was 0.03 , less than 0.05 , which satisfies the criteria. The root mean square error of approximation (RMSEA) was 0.03, less than 0.05, which satisfies the specified criteria, and the Critical $\mathrm{N}(\mathrm{CN})$ was 456.93 , which is greater than 200 [39]. The results showed that the model was acceptable. The determined confirmation factor has a concordance with the empirical data, as shown in Figure 2.

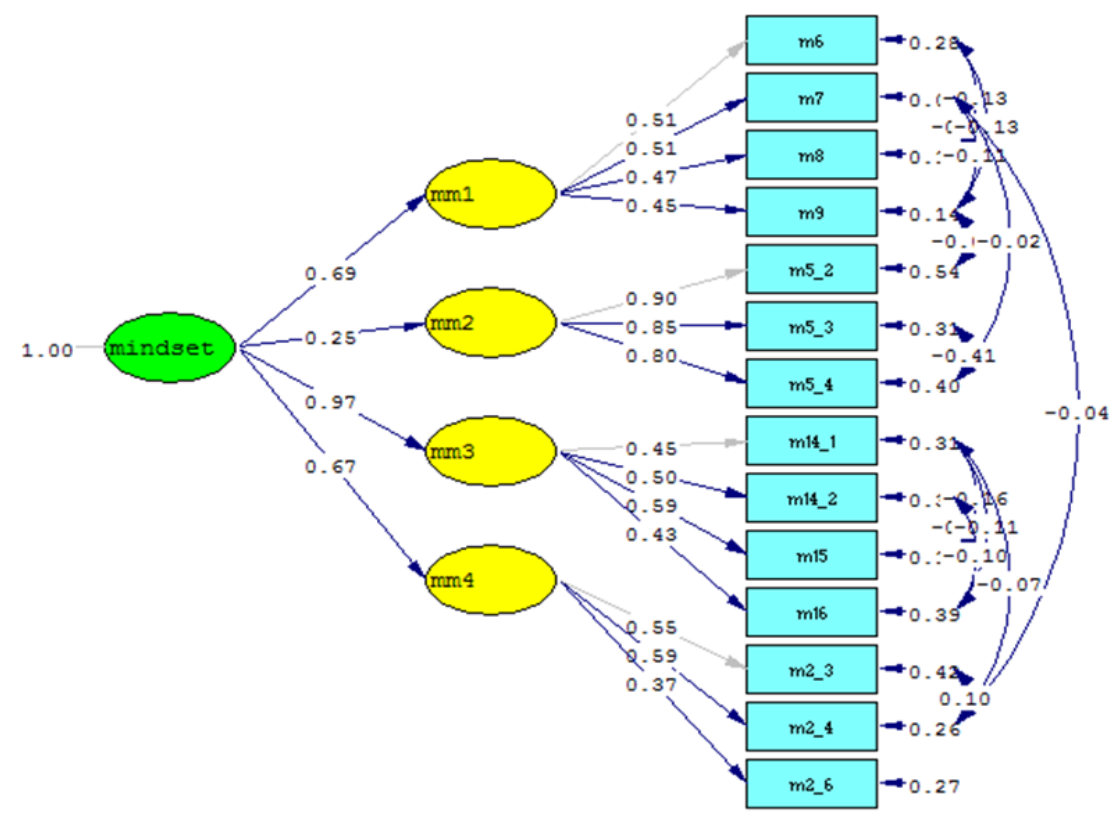

Chi-Square=76.97, df=59, P-value=0.05812, RMSEA=0.028

Figure 2. Confirmatory factor analysis of the mindful mindset

Table 4. Kaiser-Meyer-Olkin Measure of Sampling Adequacy (KMO) and Bartlett's Test of Sphericity for the correlation matrix of the mindful behaviour variables

KMO and Bartlett's Test

Kaiser-Meyer-Olkin Measure of Sampling Adequacy. .86

Note: MSA value appropriate to analyse the factors as excellent [67] up to 0.8

Approx. Chi-Square

Bartlett's Test of Sphericity

df 4011.50

Sig. 300 .00 
TEM Journal. Volume 10, Issue 3, Pages 1082-1091, ISSN 2217-8309, DOI: 10.18421/TEM103-11, August 2021.

Table 5. Eigenvalues and Percentage of variance explained by mindful behaviours

\begin{tabular}{c|l|c|c|c}
\hline Factor & \multicolumn{1}{|c|}{ Name of factors } & Eigenvalue & $\begin{array}{c}\text { Percentage of variance } \\
\text { explained }\end{array}$ & $\begin{array}{c}\text { Cumulative } \\
\text { percentage }\end{array}$ \\
\hline 1 & Behavioural control & 6.53 & 26.11 & 26.11 \\
2 & Behaviour modifications & 2.98 & 11.91 & 38.01 \\
3 & Thinking modifications & 1.80 & 7.20 & 45.22 \\
4 & Perception of the right mindset & 1.49 & 5.95 & 51.17 \\
5 & Value creation behaviour & 1.38 & 5.51 & 56.68 \\
6 & Decisions about travel/activities & 1.33 & 5.31 & 61.99 \\
7 & Travel convenience & 1.09 & 4.35 & 66.34 \\
\hline
\end{tabular}

Table 6. Factors and observed variables

\begin{tabular}{|c|c|c|c|c|}
\hline \multicolumn{3}{|r|}{ Factors } & \multicolumn{2}{|r|}{ Observed variables } \\
\hline No. & Factors & Name of factors & Factors & Description/Question in the questionnaire \\
\hline \multicolumn{5}{|c|}{ Mindful behaviour (variable: behave) } \\
\hline \multirow[t]{7}{*}{1} & bb1 & $\begin{array}{l}\text { Behavioural control } \\
\text { (to do/ not to do) }\end{array}$ & & $\begin{array}{l}\text { The experience of natural tourism enables tourists } \\
\text { to have more control of negative behaviours: }\end{array}$ \\
\hline & & & b31-6 & - To not scribble on trees, caves, or historic sites \\
\hline & & & b31-5 & - To not litter in public places \\
\hline & & & b31-1 & - To not step on coral \\
\hline & & & b31-4 & - To leave only footprints and take only pictures \\
\hline & & & b31-3 & $\begin{array}{l}\text { - To not make loud noise while travelling in } \\
\text { nature }\end{array}$ \\
\hline & & & b31-8 & $\begin{array}{l}\text { - To dress appropriately for the culture and } \\
\text { respect the place }\end{array}$ \\
\hline \multirow[t]{5}{*}{2} & bb2 & Behaviour modifications & & $\begin{array}{l}\text { To experience the way of life of the community } \\
\text { and protect the natural environment }\end{array}$ \\
\hline & & & b15-2 & - To buy more recycled products \\
\hline & & & b15-3 & - To reduce the use of disposable products \\
\hline & & & b15-4 & $\begin{array}{l}\text { - To buy products made from natural materials } \\
\text { produced by the community or more } \\
\text { environmentally friendly products }\end{array}$ \\
\hline & & & b15-1 & $\begin{array}{l}\text { - To reduce the consumption of unnecessary } \\
\text { products }\end{array}$ \\
\hline \multirow[t]{4}{*}{3} & bb3 & Thought modifications & & $\begin{array}{l}\text { The value of seeing the way of life in the } \\
\text { community and the experience of tourism in the } \\
\text { community }\end{array}$ \\
\hline & & & b5-2 & $\begin{array}{l}\text { - A change in thinking - to consume less and use } \\
\text { resources more economically }\end{array}$ \\
\hline & & & b5-1 & $\begin{array}{l}\text { - Rising awareness of simple lifestyles, turning to } \\
\text { use environmentally friendly products }\end{array}$ \\
\hline & & & b5-3 & - To reduce spending on unnecessary luxuries. \\
\hline \multirow[t]{3}{*}{4} & bb4 & $\begin{array}{l}\text { Perception of the right } \\
\text { mindset }\end{array}$ & b28 & $\begin{array}{l}\text { - Tourist should follow the way of life of the } \\
\text { community and community culture to show } \\
\text { responsibility and ethics }\end{array}$ \\
\hline & & & b29 & $\begin{array}{l}\text { - Tourism must create great relationships and } \\
\text { encourage community in the attractions }\end{array}$ \\
\hline & & & b30 & $\begin{array}{l}\text {-Tourist behavioural control represents social } \\
\text { maturity appropriate to the situation and } \\
\text { environment }\end{array}$ \\
\hline \multirow[t]{3}{*}{5} & bb5 & Value creation behaviour & b9 & $\begin{array}{l}\text { - Reuse and recycle to help to increase the } \\
\text { economic value of tourism to the community }\end{array}$ \\
\hline & & & b10 & $\begin{array}{l}\text {-Reuse and recycle to help to increase the product } \\
\text { value before turning it into trash }\end{array}$ \\
\hline & & & b11 & $\begin{array}{l}\text { - Travelling in a community can modify the } \\
\text { knowledge and experience from the community's } \\
\text { way of life to others, such as by teaching, } \\
\text { storytelling, or blog writing }\end{array}$ \\
\hline \multirow[t]{2}{*}{6} & bb6 & Decisions about travel/ & & What do tourists like about community tourism? \\
\hline & & & b22-4 & -Tourists decide to travel in communities \\
\hline
\end{tabular}




\begin{tabular}{|c|c|c|c|c|}
\hline \multicolumn{3}{|c|}{ Factors } & \multicolumn{2}{|r|}{ Observed variables } \\
\hline No. & Factors & Name of factors & Factors & Description/Question in the questionnaire \\
\hline \multicolumn{5}{|c|}{ Mindful behaviour (variable: behave) } \\
\hline & & & $\mathrm{b} 23$ & $\begin{array}{l}\text { providing environmental conservation activities } \\
\text {-Tourists decide to travel to attractions } \\
\text { considering the environment and society more } \\
\text { than convenience }\end{array}$ \\
\hline & & & b22-5 & $\begin{array}{l}\text {-Tourists decide to travel to communities with a } \\
\text { traditional way of life and culture }\end{array}$ \\
\hline \multirow[t]{4}{*}{7} & bb7 & Travel convenience & & $\begin{array}{l}\text { Accommodation selection of the tourists } \\
\text { considering these factors: }\end{array}$ \\
\hline & & & b1-1 & - Provide full facilities \\
\hline & & & b1-4 & - Prefer hotel accommodation \\
\hline & & & b7 & $\begin{array}{l}\text { - Tourists prefer to travel by private car because it } \\
\text { is more convenient than public transportation }\end{array}$ \\
\hline
\end{tabular}

$\chi^{2}=270.85, d f=237, P=0.07, G F I=0.95, A G F I=0.93, R M S E A=0.02, C N=429.01$

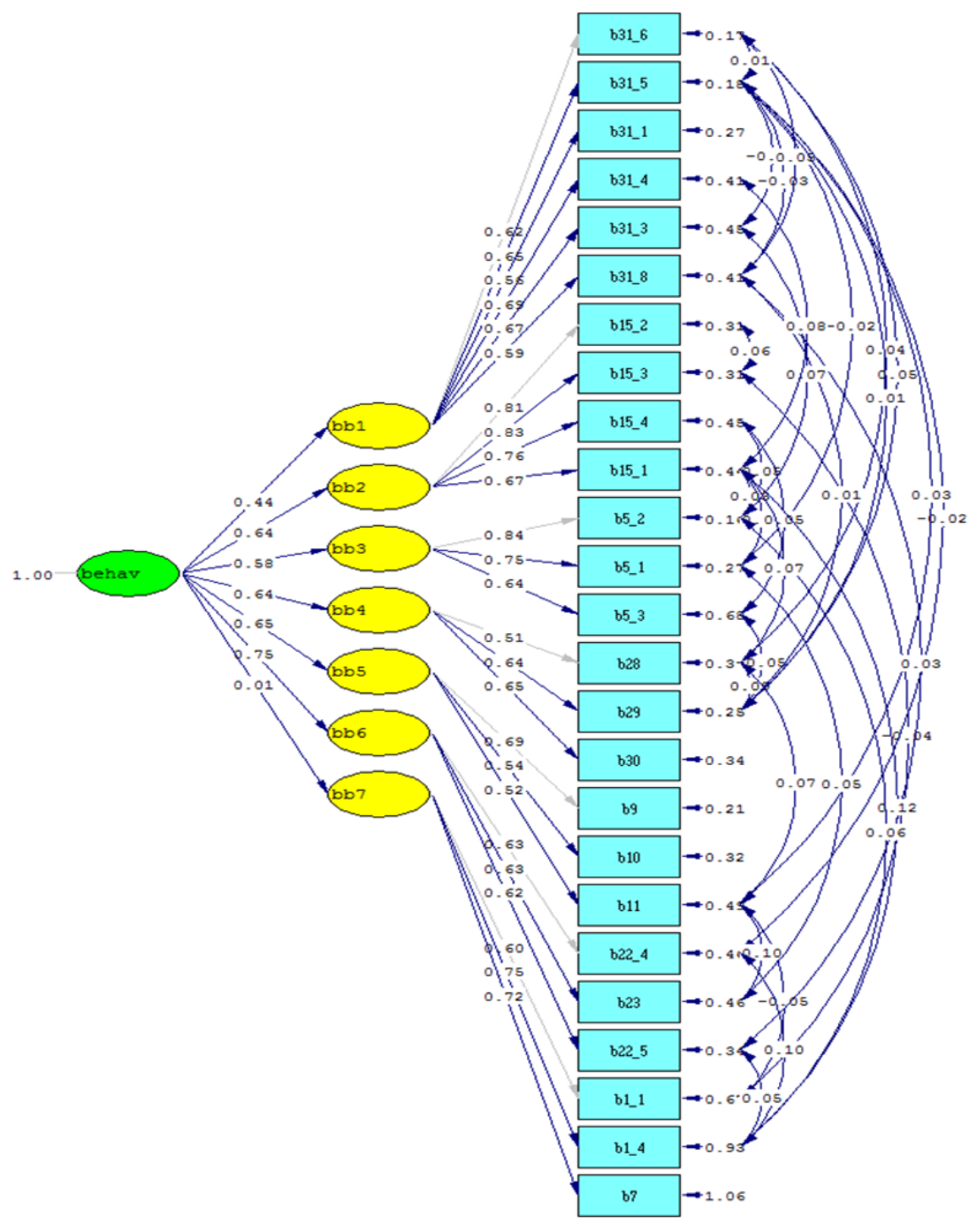

Chi-Square $=270.85, d f=237, \mathrm{P}-\mathrm{value}=0.06467, \mathrm{RMSEA}=0.019$

Figure 3. Confirmatory factor analysis of mindful behaviour

Table 4 shows the Kaiser-Meyer-Olkin measure of sampling adequacy (KMO) was 0.86, and Bartlett's test of sphericity was statistically significant $(\mathrm{Sig}=$ 0.00 ). The observed value was statistically significant at the 0.00 level, less than 0.05 , indicating that the correlation matrix of mindful behaviour variables was suitable for factor analysis.

Exploratory factor analysis of mindful behaviour considers the commonality of the observed variables, which is a correlation between variables and other variables. The values ranged from 0.55 to 0.81 , 
showing that the mentioned variables can explain the variation of other variables and can be a part of a factor.

Spindle rotation with the varimax method, considering factors loading up to 0.5 and eliminating unqualified variables, was used to analyse 51 observed variables of mindful tourism behaviour, including which variables should be in which factors. It resulted in 25 remaining variables in seven factors as shown in Tables 5 and 6 .

Confirmatory factor analysis of mindful behaviours showed that the modified model was consistent with the empirical data considering the chi-square $(\chi 2)$ of 270.85 . The number of degrees of freedom (df) was 237. The statistical significance (Pvalue) was 0.07 , greater than 0.05 , meaning the chisquare is statistically insignificant. The goodness of fit index (GFI) was 0.95, and the adjusted goodness of fit index (AGFI) was 0.93, which is better than the specified criteria. The root mean square residual (RMR) is 0.04 , less than 0.05 , which satisfies the specified criteria. The root mean square error of approximation (RMSEA) was 0.02, less than 0.05, meeting the criteria, and the Critical $\mathrm{N}$ was 429.01 , which is greater than 200 . The results indicate that the models of the confirmatory factor analysis were acceptable as determined. There was a concordance with the empirical data, as shown in Figure 3.

\section{Conclusion and Suggestions}

The analysis from applying the concept of mindful consumption in order to study the behaviour of tourists in a natural attraction area organised by a community-based tourism enterprise, Tung Yee Peng community, Koh Lanta, Krabi, found that mindful mindset variables are related to mindfulness of value, which consists of four factors. Three of the factors correspond to the mindful consumption concept of Sheth et al. [13], which include the value of community, the value of natural resources, and personal values. The last factor is the value of tourism to the community, which is a mindset arising from the experiences gained in community tourism. It creates an awareness of the value of tourism that increases economic value, cultural preservation and building community self-esteem, which all relate to Schwartz's norm activation theory [17] and research regarding the perceived value arising from tourism among tourists [3].

Mindful behaviour variables relate to six factors of behavioural expressions. The first factor corresponds to the mindful consumption concept of Sheth et al., which is behavioural control, or the control of which behaviours should or should not be performed.
The other factors -2) Behaviour modification, 3) Thought modification, 4) Perception of correct thinking, 5) Value-building behaviour, and 6) Decisions about travel and activity selection correspond to the Value-Belief-Norm (VBN) theory of Stern et al. [38]. These factors demonstrate that the development of a growth mindset leads to the development of positive behaviour.

Knowing the important factors in the mindset and behaviour of the tourists in this study will enable the development of a conceptual framework for community entrepreneurs in the tourism sector. The responsible management of the Tung Yee Peng tourism community represents a conscious and responsible operation that satisfies the mindset of tourists. It shows how to successfully develop tourism businesses by responding to the needs of tourists and raising the awareness of tourists and tourism communities at the same time. Community action as the main mechanism will not be able to adapt flexibly without cooperation from the public and private sectors, as well as national policy initiatives. Therefore, the relevant sectors need to recognise the factors related to the mindset and behaviour of tourists in order to take action from the operational level to the policy level and achieve community tourism goals leading to sustainable tourism management.

\section{References}

[1]. Kontogeorgopoulos, N., Churyen, A., \& Duangsaeng, V. (2015). Homestay tourism and the commercialization of the rural home in Thailand. Asia Pacific Journal of Tourism Research, 20(1), 29-50.

[2]. Epler Wood, M. (2005). Stepping up: Creating a sustainable tourism enterprise strategy that delivers in the developing world. Epler Wood Report (October). EsplerWood International, downloaded at www. eplerwood. com. Accessed, 24(9), 2007.

[3]. Jamal, S. A., Othman, N. A., \& Muhammad, N. M. N. (2011). Tourist perceived value in a community-based homestay visit: An investigation into the functional and experiential aspect of value. Journal of Vacation Marketing, 17(1), 5-15.

[4]. Addis, M., \& Holbrook, M. B. (2001). On the conceptual link between mass customisation and experiential consumption: an explosion of subjectivity. Journal of Consumer Behaviour: An International Research Review, 1(1), 50-66.

[5]. Noypayak, W. (2009). Value dimensions of Thailand as perceieved by U.K. tourists. Ramkhamhaeng University International Journal, 3(1), 141-154.

[6]. Klenosky, D. B. (2002). The "pull" of tourism destinations: A means-end investigation. Journal of travel research, 40(4), 396-403.

[7]. Shaw, G., \& Williams, A. M. (2004). Tourism and tourism spaces. Sage. 
[8]. Arva, L., and Deli-Gray, Z. (n.d.). New types of tourism and tourism marketing in the post-industrial world. Agroinform Publishing House, Budapest.

[9]. Sheth, J. N., Sethia, N. K., \& Srinivas, S. (2011). Mindful consumption: a customer-centric approach to sustainability. Journal of the academy of marketing science, 39(1), 21-39.

[10]. Bloom, B. S., Engelhart, M. D., Furst, E. J., Hill, W. H., and Krathwohl, D. R. (1956). Taxonomy of Educational Objective, The Cognitive Domani. New York: Longmans.

[11]. Young, W., Hwang, K., McDonald, S., \& Oates, C. J. (2010). Sustainable consumption: green consumer behaviour when purchasing products. Sustainable development, 18(1), 20-31. DOI: 10.1002/sd.394.

[12]. Ajzen, I. (2005). Attitudes, personality, and behavior. Open Univ Pr.

[13]. Gollwitzer, P. M. (1993). Goal achievement: The role of intentions. European review of social psychology, 4(1), 141-185.

[14]. Ronis, D. L., Yates, J. F., \& Kirscht, J. P. (1989). Attitudes, decisions, and habits as determinants of repeated behavior. Attitude structure and function, 213, 39.

[15]. Schwartz, S. H. (1973). Normative explanations of helping behavior: A critique, proposal, and empirical test. Journal of experimental social psychology, 9(4), 349-364.

[16]. Stern, P. C., Dietz, T., \& Kalof, L. (1993). Value orientations, gender, and environmental concern. Environment and behavior, 25(5), 322-348.

[17]. Wheale, P., \& Hinton, D. (2007). Ethical consumers in search of markets. Business Strategy and the Environment, 16(4), 302-315.

DOI: $10.1002 /$ bse.484.

[18]. Dweck, C. S. (2008). Mindset: The new psychology of success. Random House Digital, Inc..

[19]. Murphy, M. C., \& Dweck, C. S. (2016). Mindsets shape consumer behavior. Journal of Consumer Psychology, 26(1), 127-136.

[20]. Park, J. K., \& John, D. R. (2010). Got to get you into my life: Do brand personalities rub off on consumers?. Journal of consumer research,37(4), 655-669.

[21]. Guo, L., Lotz, S. L., Tang, C., \& Gruen, T. W. (2015). The Role of Perceived Control in Customer Value Cocreation and Service Recovery Evaluation. Journal of Service Research, 1, 18.

Retrieved

from http://jsr.sagepub.com/content/early/2015/07/28/1094 670515597213.full.pdf + html.

[22]. Ndubisi, N. O. (2012). Relationship quality: upshot of mindfulness-based marketing strategy in small organisations. International Journal of Quality \& Reliability Management, 29(6), 626-641.

[23]. Champaratna, S. (2014). The Lifelong Learning Mindset Model of Private University Undergraduate Students, Bangkok Metropolis. Journal of Behavioral Science Vol, 20(1).

[24]. Borgmann, A. (2000). The moral complexion of consumption. Journal of Consumer Research, 26(4), 418-422.
[25]. Whybrow, P. C. (2005). American Mania : When more is not enough. New York: W. W. Norton.

[26]. Kilbourne, W. E. (2006). The Role of the Dominant Social Paradigm in the Quality of Life/Environmental Interface. Applied Research in Quality of Life, 1(1), 39-61.

[27]. McCollough, J. (2007). The effect of income growth on the mix of purchases between disposable goods and reusable goods. International Journal of Consumer Studies, 31(3), 213-219.

[28]. Heiskanen, E. (1996, March). Conditions for product life extension. In Proceedings of the 3rd Conference of the Nordic Business Environmental Management Network. Aarhus. Denmark (pp. 395-408).

[29]. Veblen, T. (1899). The theory of the leisure class. New York: Modern Library.

[30]. Gordon, J. M., \& Schaller, T. K. (2014). The role of mindfulness in entrepreneurial market analysis. Journal of Research in Marketing and Entrepreneurship, 16(1), 7-25.

[31]. Kayat, K., Ramli, R., Mat-Kasim, M., \& AbdulRazak, R. (2014). Community-based rural tourism as a sustainable development alternative: An analysis with special reference to the community-based rural homestay programmes in Malaysia. Theory and Practice in Hospitality and Tourism Research, 223.

[32]. Brundtland, G. H. (1987). Brundtland report. Our common future. Comissão Mundial, 4(1), 17-25.

[33]. Camilleri, M. (2014). Advancing the sustainable tourism agenda through strategic CSR perspectives. Tourism Planning \& Development, 11(1), 42-56. http://doi.org/10.1080/21568316.2013.839470

[34]. Wang, C. L., \& Ahmed, P. K. (2004). The development and validation of the organisational innovativeness construct using confirmatory factor analysis. European Journal of Innovation Management, 7(4), 303-313.

https://doi.org/10.1108/14601060410565056

[35]. Supamas Angsuchote et al. (2008). Statistics for Research on Social and Behavioral Sciences : Technique for Use of LISREL. Bangkok: Mission Media.

[36]. Wang, C. L., \& Ahmed, P. K. (2004). The development and validation of the organisational innovativeness construct using confirmatory factor analysis. European Journal of Innovation Management, 7(4), 303-313. https://doi.org/10.1108/14601060410565056

[37]. Wheale, P., \& Hinton, D. (2007). Ethical consumers in search of markets. Business Strategy and the Environment, 16(4), 302-315.

DOI: $10.1002 /$ bse. 484

[38]. Zhang, Y., Cole, S. T., \& Chancellor, C. H. (2013). Residents' preferences for involvement in tourism development and influences from individual profiles. Tourism Planning \& Development, 10(3), 267-284.

[39]. Young, W., Hwang, K., McDonald, S., \& Oates, C. J. (2010). Sustainable consumption: green consumer behaviour when purchasing products. Sustainable development, 18(1), 20-31. DOI: 10.1002/sd.394. 